\title{
Effects of limiting nutrients and $N: P$ ratios on the phytoplankton growth in a shallow hypertrophic reservoir
}

\author{
Ho-Sub Kim · Soon-Jin Hwang • Jae-Ki Shin • \\ Kwang-Guk An · Chun Gyeong Yoon
}

Published online: 2 May 2007

(C) Springer Science+Business Media B.V. 2007

\section{Erratum to: Hydrobiologia 581:255-267 DOI 10.1007/s10750-006-0501-9}

The addresses of three authors of this article were given incorrectly. The correct details are shown below. The publishers apologise for this error.

The online version of the original article can be found at http://dx.doi.org/10.1007/s10750-006-0501-9

Guest editors: B. Qin, Z. Liu \& K. Havens

Eutrophication of shallow lakes with special reference to Lake Taihu, China

H.-S. Kim · S.-J. Hwang $(\bowtie) \cdot C$. G. Yoon Department of Environmental Science, Konkuk University, Seoul 143-701, Korea

e-mail: sjhwang@konkuk.ac.kr

J.-K. Shin

Korea Institute of Water and Environment, Korea

Water Resources Corporation, Daejon 305-730,

Korea

K.-G. An

School of Bioscience and Biotechnology, Chungnam

National University, Daejon 305-764, Korea

Present Address:

H.-S. Kim

Han River Environmental Research Laboratory,

National Institute of Environmental Research,

Gyeonggi 476-823, Korea 